\title{
A UNIVERSALIZAÇÃO DOS DIREITOS HUMANOS E A IGUALDADE DE GÊNEROS: ANÁLISE DO CASO ALYNE V. BRASIL
}

Fernanda Prado*

\begin{abstract}
RESUMO: O presente estudo demonstra a necessidade de se considerar as características das mulheres no momento de elaboração e aplicação de documentos internacionais de defesa dos direitos humanos, para atingir a igualdade de gêneros e a consequente universalização dos referidos direitos. Por meio do método dedutivo, e mediante pesquisas bibliográficas, apresenta um breve histórico dos direitos humanos das mulheres. Em seguida, descreve a importância de se sopesar as particularidades femininas para a efetivação de seus direitos. Por fim, demonstra como essa prática ocorreu no caso "Alyne v. Brasil", julgado pelo Comitê sobre a Eliminação da Discriminação contra a Mulher.
\end{abstract}

PALAVRAS-CHAVE: Direitos Humanos; Gênero; Documentos de Proteção Internacional; Universalização; Caso Alyne v. Brasil

\section{THE HUMAN RIGHTS' UNIVERSALIZATION AND THE GENDER EQUALITY:}

\section{ANALYSIS OF THE ALYNE V. BRAZIL CASE}

\begin{abstract}
The present study shows the need to consider the characteristics of women at the time of preparation and application of international human rights documents for gender equality and the consequent universalization of these rights. Through the deductive method, and through bibliographical research, it presents a brief history of women's human rights. Then it describes the importance of weighing women's particularities for the realization of their rights, especially regarding reproductive rights. Finally, it shows how this practice occurred in the case "Alyne v. Brazil", judged by the Committee on the Elimination of Discrimination against Women.
\end{abstract}

KEYWORDS: Human rights; Genre; International Protection Documents; Universalization; Alyne v. Brazil's Case.

\footnotetext{
* Bacharel em Direito pela Universidade Estadual de Londrina - UEL. Mestranda do Programa de Mestrado em Ciência Jurídica do Centro de Ciências Sociais Aplicadas - Campus Jacarezinho - UENP. E-mail: fernandaa_pradoo@hotmail.com
} 


\section{INTRODUÇÃO}

A tutela de direitos histórica e axiologicamente definidos pela humanidade como imprescindíveis para assegurar e compor sua dignidade fundamenta a democracia e garante a respectiva coesão e harmonia sociais.

Ao longo do tempo, direitos tidos como inerentes à condição de ser do indivíduo foram se afirmando, ao serem reconhecidos e protegidos por instrumentos internacionais, diante da constatação da indispensabilidade de um sistema universal de proteção de garantias fundamentais da pessoa para a própria continuidade da humanidade. Tem-se, assim, os direitos humanos.

Todavia, a construção, o progresso e a efetivação dos direitos humanos dos homens e das mulheres ocorreu de forma divergente, existindo uma evidente defasagem na defesa e no exercício desses direitos com relação ao sexo feminino.

Esse fato decorreu (e decorre) da resistência da sociedade em modificar o entendimento culturalmente difundindo de hierarquização do homem, o que fortalece violências e discriminações contra as mulheres e, ainda, inviabiliza a universalização dos direitos humanos,

Nesse sentido, utilizando o método dedutivo, o presente estudo inicia-se com um breve histórico dos direitos humanos das mulheres, destacando os principais documentos internacionais elaborados para a garantia da liberdade e da igualdade dos seres humanos. No mesmo título, demonstra o descompasso entre a defesa dos interesses masculinos e femininos, destacando que o caminho a ser percorrido para o exercício indistinto dos direitos humanos é mais extenso e tortuoso para as mulheres.

Consequentemente, instrumentos normativos internacionais específicos passaram a vigorar para a reversão dessa manifesta discriminação. Dessa forma, é feita uma análise individual da Convenção Sobre a Eliminação de Todas as Formas de Discriminação Contra a Mulher, primeiro documento internacional que tratou amplamente dos direitos humanos das mulheres a fim de promover a igualdade de gêneros.

A partir disso, o título seguinte ressalta a importância de se considerar as peculiaridades do sexo feminino, principalmente no momento de se reconhecer e de se estabelecer mecanismos de proteção de direitos que requerem uma diferenciação quando aplicados em favor das mulheres. 
Por fim, com base nas premissas anteriores - descompasso do progresso dos direitos humanos e discriminação das mulheres para seu exercício - , estuda-se a decisão proferida pelo Comitê da Convenção Sobre a Eliminação de Todas as Formas de Discriminação Contra a Mulher, no caso "Alyne v. Brasil”, que reconheceu a discriminação sofrida por Alyne da Silva Pimentel Teixeira com relação ao exercício do direito à saúde, notadamente o direito reprodutivo, e a respectiva responsabilidade do Estado brasileiro a ressarcir os danos (materiais e morais) reconhecidos e a adotar políticas públicas destinadas a resguardar, isonomicamente, o direito à saúde da mulher.

\section{HISTÓRICO DOS DIREITOS HUMANOS DAS MULHERES}

Uma das características dos direitos humanos consiste na sua historicidade, na medida em que referidos direitos, apesar de serem entendidos como inerentes à condição de ser humano, são afirmados ao longo da dinâmica histórico-social própria das relações pessoais.

Nesse sentido, o reconhecimento, a positivação, o progresso e a efetiva garantia desses direitos são resultados de constantes lutas da sociedade destinadas, principalmente, a demonstrar que a tutela de certas garantias é indispensável para a observância da dignidade da pessoa humana, base fundante dos preceitos que entendem o homem e a mulher como sujeitos de direitos e que norteiam os atores políticos, jurídicos e sociais na busca de uma democratização e universalização dos direitos humanos.

De acordo com o ensinamento de Bobbio (2004, p.9), referidos direitos nascem "em certas circunstâncias, caracterizados por lutas em defesa de novas liberdades contra velhos poderes, e nascidos de modo gradual, não todos de uma vez e nem de uma vez por todas".

Essa qualidade dos direitos humanos decorre justamente da dialética inerente às relações sociais, especialmente porque a edição de documentos e a instituição de mecanismos de proteção de determinadas liberdades estão condicionadas às circunstâncias e às necessidades valoradas em certo período histórico.

Com base nisso, o presente capítulo apresentará um breve retrospecto dos direitos humanos, destacando os principais instrumentos normativos elaborados para sua proteção, com especial atenção ao progresso na garantia dos direitos humanos das mulheres. 
Antecedentes históricos como a Magna Charta Libertatum, de 1215, a Petition of Right, de 1628, e o Habeas Corpus ACT, de 1679, todos da Inglaterra, e como a Declaração de Direitos de Virgínia e a Declaração de Independência dos Estados Unidos da América, ambas de 1776 e decorrentes da realidade histórica daquele país, contribuíram para o desenvolvimento de declarações de direitos fundamentais no final do século XVIII até meados do século XX.

A Declaração de Direito do Bom Povo de Virgínia, por exemplo, foi, para Comparato (1999, p. 83), “o ato inaugural da democracia moderna, combinando, sob o regime constitucional, a representação popular com a limitação de poderes governamentais e o respeito aos direitos humanos".

Contudo, o documento mais importante para o progresso e a universalização dos direitos humanos foi a Declaração dos Direitos do Homem e do Cidadão, de 1789, surgida no âmbito da Revolução Francesa, como resultado da busca e da efetivação, pela burguesia, dos ideais de liberdade, igualdade e fraternidade. Referida declaração procurou reconhecer direitos para toda a humanidade, ao afirmar, em seu artigo $1^{\circ}$, que "os homens nascem e são livres e iguais em direitos".

Não obstante, a marca cultural da desigualdade entre os gêneros impediu o reconhecimento e a extensão dos direitos e garantias defendidos na Revolução Francesa às mulheres. Fatos como a decapitação da francesa Olympe de Gouges, autora da Declaração do Direitos da Mulher e da Cidadã de 1791, evidenciam a resistência e o retrocesso da sociedade (inclusive de mulheres) em alterar a ideia de natural hierarquização do masculino sobre o feminino difundida ao longo dos séculos.

Tedeschi; Colling (2014, p. 46) constatam que

A insistência sobre uma natureza feminina familiar e doméstica e uma natureza masculina social e política, foi abundante no discurso revolucionário que instalou a igualdade e a cidadania, deixando a impressão de que a própria natureza prescreveu para cada sexo as respectivas funções.

Esse cenário corroborou para um descompasso no avanço da proteção dos direitos humanos dos homens e das mulheres, com reflexos nos dias atuais, já que, apesar da existência de um longo caminho a ser percorrido pela comunidade internacional para a garantia dos direitos fundamentais dos seres humanos, a batalha para a efetivação dos direitos humanos das mulheres mostra-se ainda mais extensa e custosa.

Rev. de Gênero, Sexualidade e Direito | e-ISSN: 2525-9849 | Porto Alegre | v. 4 | n. 2 | p. 1-18 | Jul/Dez. 2018 
Posteriormente, com o fim da Segunda Guerra Mundial, e diante de sistêmicas e acentuadas violações de direitos humanos, proclamou-se a Declaração Universal de Direitos Humanos (DUDH), de 1948, objetivando assegurar, globalmente, a dignidade da pessoa humana, intrinsecamente ligada à garantia de um conjunto de normas e preceitos que possibilitem o exercício de direitos essenciais de forma livre, autônoma e indistinta pelos indivíduos.

Nesse sentido, Bobbio (2004, p. 60) destaca que

[...] a Declaração Universal dos Direitos do Homem, de 10 de dezembro de 1948, colocou as premissas para transformar também os indivíduos singulares, e não mais apenas os Estados, em sujeitos jurídicos do direito internacional, tendo assim, por conseguinte, iniciado a passagem para uma nova fase do direito internacional, a que torna esse direito não apenas o direito de todas as gentes, mas o direito de todos os indivíduos.

Por outro lado, Piovesan (2013, p. 239) ressalva que

[...] sob um enfoque estritamente legalista (não compartilhado por este trabalho), a Declaração Universal, em si mesma, não apresenta força jurídica obrigatória e vinculante. Nessa visão, assumindo a forma de declaração (e não de tratado), vem a atestar o reconhecimento universal de direitos humanos fundamentais, consagrando um código comum a ser seguido por todos os Estados.

Assim, após a adoção da mencionada Declaração e para solucionar a questão de inexistência de força vinculante, entendeu-se que o documento deveria ser convertido em tratado internacional, sendo que o

[...] processo de "juridicização" da Declaração começou em 1949 e foi concluído apenas em 1966, com a elaboração de dois tratados internacionais distintos - o Pacto Internacional dos Direitos Civis e Políticos e o Pacto Internacional dos Direitos Econômicos, Sociais e Culturais - que passaram a incorporar os direitos constantes da Declaração Universal.

Especificamente quanto às diferenciações de gênero verificadas na elaboração e na aplicação dos instrumentos normativos internacionais anteriores, a Declaração Universal de Direitos Humanos progrediu, ao substituir a expressão "direitos do homem”, regularmente utilizada, para anunciar que "Todos os seres humanos nascem livres e iguais em dignidade e direitos" (DUDH, art. $1^{\circ}$ ). 
Em que pese a pretensão de universalização dos direitos humanos, a referida declaração apresentou-se insuficiente para reverter o enraizado quadro de discriminação e a consequente violência contra as mulheres. Portanto, somado ao sistema geral de proteção dos direitos humanos, viu-se a necessidade de criação e do emprego de instrumentos especiais reservados à salvaguarda dos direitos individuais e sociais das mulheres.

Por conseguinte, em 1979, as Nações Unidas aprovaram a Convenção sobre a Eliminação de Todas as Formas de Discriminação contra a Mulher (CEDAW, sigla em inglês), com fundamento "na dupla obrigação de eliminar a discriminação e de assegurar a igualdade. Trata do princípio da igualdade seja como obrigação vinculante, seja como objetivo" (PIOVESAN, 2013, p. 269).

Conforme será abordado, a CEDAW figura como relevante instrumento de defesa dos direitos humanos das mulheres, sendo o primeiro a dispor, de forma ampla, sobre esse tema. Posteriormente, outros documentos específicos foram elaborados também com esse fim, como a Declaração sobre a Eliminação da Violência contra a Mulher, de 1993 e a Convenção Interamericana para Prevenir, Punir e Erradicar a Violência contra a Mulher, de 1994.

Realizado um conciso histórico da afirmação dos direitos humanos, com especial atenção ao crescimento, ainda que modesto, das conquistas relativas aos direitos humanos das mulheres, passa-se ao estudo particular da CEDAW.

\subsection{A Convenção Sobre a Eliminação de Todas as Formas de Discriminação Contra a Mulher}

A Convenção sobre a Eliminação de Todas as Formas de Discriminação contra a Mulher, aprovada pelas Nações Unidas em 1979, também conhecida como Convenção da Mulher, integra o sistema especial de proteção dos direitos humanos, já que direcionada à proteção e garantia de direitos humanos específicos das mulheres.

Referida convenção constitui importante instrumento internacional de proteção dos direitos das mulheres, cujo objetivo principal é a supressão de qualquer forma de discriminação, para, assim, atender o princípio da igualdade e a dignidade da pessoa humana, consagrados absolutamente pela Declaração Universal dos Direitos Humanos.

Nesse sentido, Piovesan (2013, p. 260-261) esclarece que

Rev. de Gênero, Sexualidade e Direito | e-ISSN: 2525-9849 | Porto Alegre | v. 4 | n. 2 | p. 1 - 18 | Jul/Dez. 2018 
[...] o sistema especial de proteção é voltado, fundamentalmente, à prevenção da discriminação ou à proteção de pessoas ou grupos de pessoas particularmente vulneráveis, que merecem proteção especial. Daí se apontar não mais ao indivíduo genérica e abstratamente considerado, mas ao indivíduo "especificado", considerando-se categorizações relativas ao gênero, idade, etnia, raça etc. $\mathrm{O}$ sistema internacional passa a reconhecer direitos endereçados às crianças, aos idosos, às mulheres, às pessoas vítimas de tortura, às pessoas vítimas de discriminação racial, entre outros.

A formulação de instrumentos protetivos específicos justifica-se exatamente pela condição de maior vulnerabilidade de determinado sujeito de direitos (no caso, as mulheres), especialmente diante da ineficácia do sistema geral de proteção de direitos humanos para resguardar e viabilizar o exercício de direitos fundamentais livre de qualquer discriminação baseada no sexo.

De acordo com o Departamento de Assuntos Econômicos e Sociais das Nações Unidas (DESA, 1999, tradução minha), a CEDAW

[...] é o único documento para as mulheres surgido na Década das Nações Unidas que legalmente obriga os governos a eliminarem a discriminação contra as mulheres, concedendo-lhes direitos legais em igualdade de oportunidades. Adotado por unanimidade pela Assembleia Geral em 1979 e tendo entrado em vigor como tratado vinculativo em 3 de Setembro de 1981, a Convenção constitui o quadro de ação para promover os direitos humanos fundamentais das mulheres ${ }^{1}$.

De igual modo, Pimentel (2008, p. 15) destaca a importância da referida Convenção para fins de resguardar os interesses das mulheres, considerando que

Resultou de iniciativas tomadas dentro da Comissão de Status da Mulher (CSW, sigla em inglês), órgão criado dentro do sistema das Nações Unidas, em 1946, com o objetivo de analisar e criar recomendações de formulações de políticas aos vários países signatários da Convenção, visando aprimorar o status da mulher

Dessa forma,

A Convenção da Mulher deve ser tomada como parâmetro mínimo das ações estatais na promoção dos direitos humanos das mulheres e na repressão as suas violações, tanto no âmbito público como no âmbito privado. A CEDAW

\footnotetext{
${ }^{1}[\ldots]$ is the only document to have emerged from the United Nations Decade for Women that legally obliges Governments to eliminate discrimination against women by granting them legal rights as well as equal opportunities. Adopted unanimously by the General Assembly in 1979 and having entered into force as a binding treaty on 3 September 1981, the Convention constitutes the framework of action to promote the fundamental human rights of women.
}

Rev. de Gênero, Sexualidade e Direito | e-ISSN: 2525-9849 | Porto Alegre | v. 4 | n. 2 | p. 1 - 18 | Jul/Dez. 2018 
é a grande Carta Magna dos direitos das mulheres e simboliza o resultado de inúmeros avanços principiológicos, normativos e políticos construídos nas últimas décadas, em um grande esforço global de edificação de uma ordem internacional de respeito à dignidade de todo e qualquer ser humano (PIMENTEL, 2008, p. 17).

O citado documento foi assinado por 190 países (2018), sendo ratificado pelo Brasil no ano de 1984 (Decreto $\mathrm{n}^{\mathrm{o}} 89.460$ ), com reservas ao artigo 15 , parágrafo $4^{\text {o2}}$, que prevê a igualdade de direitos entre homens e mulheres quanto à liberdade de movimento e de escolha de residência e domicílio, e ao artigo 16 , parágrafo $1^{\circ}$ (a), (c), $(\mathrm{g})$, e $(\mathrm{h})^{3}$, da Convenção, referentes à igualdade entre homens e mulheres nas relações familiares. As aludidas reservas foram retiradas pelo Estado brasileiro apenas em 1994.

Piovesan (2012, p. 76-77) explica que, apesar do amplo número de adesão, a Convenção da Mulher foi a que mais recebeu reservas pelos Estados signatários no âmbito de direitos humanos, "especialmente no que tange à igualdade entre homens e mulheres na família. Tais reservas foram justificadas com base em argumentos de ordem religiosa, cultural ou mesmo legal $[\ldots] "$.

Essa resistência no reconhecimento da igualdade de gêneros é reflexo e demonstra uma cultura internacional patriarcal, que aliena as mulheres do espaço e das questões públicas e limita o seu papel social ao exercício de atividades privadas, normalmente vinculadas ao âmbito doméstico e familiar, mas sempre subordinadas à figura do homem. A mencionada situação legitima, uma vez mais, a aprovação de tratados internacionais de caráter especial, destinados a extinguir as desigualdades existentes entre homens e mulheres, que ferem diretamente o ideal de direitos humanos buscado pela comunidade internacional.

\footnotetext{
${ }^{2}$ Artigo 15

[...]

4. Os Estados-Partes concederão ao homem e à mulher os mesmos direitos no que respeita à legislação relativa ao direito das pessoas à liberdade de movimento e à liberdade de escolha de residência e domicílio.

${ }^{3}$ Artigo 16

1. Os Estados-Partes adotarão todas as medidas adequadas para eliminar a discriminação contra a mulher em todos os assuntos relativos ao casamento e às relações familiares, em particular, com base na igualdade entre homens e mulheres, assegurarão:

a) $\mathrm{O}$ mesmo direito de contrair matrimônio;

$[\ldots]$

c) Os mesmos diretos e responsabilidades durante o casamento e por ocasião de sua dissolução;

[...]

g) Os mesmos direitos pessoais como marido e mulher, inclusive o direito de escolher sobrenome, profissão e ocupação;

h) Os mesmos direitos a ambos os cônjuges em matéria de propriedade, aquisição, gestão, administração, gozo e disposição dos bens, tanto a título gratuito quanto a título oneroso.
}

Rev. de Gênero, Sexualidade e Direito | e-ISSN: 2525-9849 | Porto Alegre | v. 4 | n. 2 | p. 1-18 | Jul/Dez. 2018 
Consequentemente, esse quadro de intrínsecas e ilegais distinções de gênero impõe, não apenas a enunciação de direitos das mulheres, mas sim a verdadeira adoção de medidas que possibilitem o efetivo exercício dos direitos humanos femininos.

Foi com base nisso que a CEDAW, em seu artigo 17, instituiu o Comitê sobre a Eliminação da Discriminação contra a Mulher, cuja atribuição consiste no exame dos "progressos alcançados na aplicação desta Convenção". Em complemento, as Nações Unidas aprovaram, em 1999, o protocolo facultativo à Convenção da Mulher, que conferiu jurisdição ao citado Comitê, já que reconheceu sua competência para receber e processar noticiadas violações dos direitos previstos no documento internacional. Esse protocolo foi ratificado pelo Estado brasileiro no ano de 2002 (Decreto $\mathrm{n}^{\circ}$ 4.377).

Apesar da inexistência de caráter vinculante das decisões proferidas pelo Comitê, sua força política, tanto no monitoramento da implementação da CEDAW, quanto na emissão de recomendações gerais e específicas constitui importante meio voltado à proteção dos direitos humanos das mulheres.

\section{A OBSERVÂNCIA DAS CARACTERÍSTICAS INTRÍNSECAS ÀS MULHERES COMO CONDICIONANTE À DECISIVA UNIVERSALIZAÇÃO DOS DIREITOS HUMANOS}

A universalização dos diretos humanos implica, necessariamente, na possibilidade de seu exercício isonômico e isento de qualquer discriminação.

Estabelecida essa premissa, determinadas circunstâncias que dificultam a garantia e o acesso a direitos de maneira indiscriminada, como questões de gênero, classe e raça ou etnia, precisam ser consideradas particularmente no momento da elaboração e da aplicação de diplomas legais voltados à defesa dos direitos humanos.

Nesse sentido, a ideia de superioridade do gênero masculino, cultura e amplamente difundida, que reserva à mulher o espaço da vida privada e desvaloriza o que se codifica como feminino, criou obstáculos à garantia dos direitos humanos em favor das mulheres, causando uma desarmonia atual entre os gêneros na efetivação desses direitos.

Perrot (1989, p.10) retrata a imagem da mulher na história imersa em estereótipos que as enquadravam como 
[...] mulheres vociferantes, megeras a partir do momento em que abrem a boca, histéricas do momento em que gesticulam. A visão que se tem das mulheres funciona como um indicador: elas são consideradas raramente por si mesmas, mas com freqüência (sic) como sintomas de febre ou de abatimento.

Diante desse contexto, Zinani (2006, p. 102) enfatiza que, na busca da emancipação das mulheres,

[...] é necessário desconstruir os conceitos tradicionais, redesenhar os papéis de homens e mulheres e prepará-los para assumir as novas tarefas com igualdade e respeito. Talvez a transformação do homem seja a tarefa mais difícil, pois, como a mulher, precisa vencer condicionamentos ancestrais que pertencem ao inconsciente coletivo, além disso, necessita da aceitação do grupo e da própria mulher.

A ausência da real concretização dos direitos humanos das mulheres, fundamentada na existência de discriminações, resulta, por exemplo, em significativos índices de violência e de mortalidade materna por causas evitáveis.

Referidas situações impõem e legitimam a criação e a realização de instrumentos internacionais especialmente designados para a defesa dos interesses femininos e, consequentemente, para a promoção da igualdade dos gêneros e a universalização dos direitos humanos, conforme exposto.

Por consequência, os Estados devem adotar e desenvolver medidas que se preocupem e resguardem as condições particulares do gênero feminino no momento de garantia dos seus direitos. Dentro desse contexto, destaca-se o direito à saúde como um ótimo referencial exemplificativo.

As diferenças biológicas entre homens e mulheres são visivelmente percebidas e cientificamente estudadas, sendo que, em razão das especificidades do sistema reprodutivo feminino, a prestação do referido serviço deve ocorrer de maneira diferenciada.

É certo que o direito à saúde é assegurado a todos os indivíduos indistintamente, mas as características das mulheres precisam ser ponderadas, notadamente no que se refere aos seus direitos reprodutivos, a fim de que seja assegurada a assistência médica preventiva e hospitalar livre de qualquer discriminação.

Isso porque,

É na ordem da sexualidade que se colocam a afirmação e a vontade de criação das mulheres. Em outras palavras, é reivindicando uma sexualidade

Rev. de Gênero, Sexualidade e Direito | e-ISSN: 2525-9849 | Porto Alegre | v. 4 | n. 2 | p. 1-18 | Jul/Dez. 2018 
independente das funções de reprodução e de maternidade que as mulheres se constituem verdadeiramente em movimento social e avançam o mais longe possível - mais longe do que através da luta pela igualdade e contra a discriminação (TOURAINE, 2006, p. 217)

Nesse sentido, a universalização dos direitos humanos somente será possível a partir da previsão e da aplicação desses direitos de maneira uniforme, o que implica na preocupação e implementação de instrumentos que considerem as condições peculiares daqueles que se encontram em situação de vulnerabilidade, como acontece com as mulheres.

Com base nisso, o caso "Alyne v. Brasil" estudado a seguir, demonstra a preocupação internacional em modificar as desigualdades de gênero existentes e, assim, universalizar os direitos humanos, ao analisar noticiada discriminação da mulher no exercício do direito à saúde e à vida.

\subsection{Caso Alyne v. Brasil}

Em 30 de novembro de 2007, Maria de Lourdes da Silva Pimentel, representada pelo Centro de Direitos Reprodutivos e pela Advocacia Cidadã pelos Direitos Humanos, encaminhou o Ofício n ${ }^{\circ}$ 17/2008 ao Comitê da CEDAW, noticiando suposta discriminação de gênero da vítima Alyne da Silva Pimentel Teixeira pelo Estado brasileiro.

De acordo com os fatos narrados, Alyne da Silva Pimentel Teixeira, mulher, brasileira, de 28 anos, afrodescendente e grávida, foi, na data de 11 de novembro de 2002, à Casa de Saúde Nossa Senhora da Glória, com sintomas de gravidez de alto risco. Após atendimento médico, determinou-se seu retorno para casa, sem a realização de qualquer exame clínico.

Nos dois dias seguintes, os sintomas agravaram-se e, com o retorno à clínica, os médicos não conseguiram detectar os batimentos cardíacos do feto. Consequentemente, o parto foi induzido (feto natimorto), porém a cirurgia para a extração da placenta ocorreu apenas catorze horas mais tarde.

Em razão de complicações dos sintomas clínicos de Alyne, houve a necessidade de sua transferência a um serviço de saúde mais especializado, o que ocorreu somente oito horas depois do momento em que os médicos entraram em contato com Hospital Geral de Nova Iguaçu (único hospital que possuía lugar disponível). Alyne faleceu menos de 24 horas depois de sua transferência, devido a uma hemorragia digestiva. 
Com base nisso, afirmou-se a:

1) violação do direito de acesso à justiça (art. 2 da Convenção), já que a ação civil indenizatória proposta pela família de Alyne na justiça brasileira ainda pendia de julgamento (após 04 anos de tramitação); e

2) violação do direito à saúde sem discriminação (art. 12 da Convenção) e do direito à vida (art. 1 da Convenção), já que o Estado brasileiro havia falhado em garantir à Alyne serviços de saúde oportunos e de qualidade durante a gravidez e o parto, o que colocou em risco a sua vida, a sua saúde e seu direito de viver livre de discriminação. Isto foi agravado pelo fato de Alyne ser uma mulher, ser negra e ser pobre.

Em sua defesa, o Estado brasileiro alegou, resumidamente, a inexistência de nexo causal entre a condição de mulher de Alyne da Silva Pimentel Teixeira e os possíveis erros médicos cometidos, sendo que a morte da citada vítima ocorreu em razão da deficiência na prestação do serviço público de saúde. Destacou, ainda, a adoção e o desenvolvimento de políticas públicas destinadas a assegurar os direitos humanos das mulheres, principalmente no que se refere ao acesso aos serviços de saúde sem discriminação.

Após o exame de admissibilidade do ofício $n^{\circ} 17 / 2008$, o Comitê passou a analisar o mérito da demanda, entendendo, de início, que a morte de Alyne da Silva Pimentel Teixeira tinha relação a questões maternas, bem como que a afirmação do Estado brasileiro, no sentido de inexistência de causalidade entre o sexo biológico de Alyne e seu óbito, não deveria ser acolhida.

Nesse sentido, fundamentou que

[...]

7.3 Embora o Estado-parte argumente que a morte da Sra. da Silva Pimentel Teixeira não teve relação com fatores maternos e que a provável causa da morte foi hemorragia digestiva, observa o Comitê que a sequência de eventos descritos pelo autor e não impugnada pelo Estado-parte, bem como a opinião de especialistas fornecidas pelo autor, indicam que sua morte teve de fato relação com complicações obstétricas relacionadas à gravidez. Suas queixas de náusea extrema e dor abdominal durante o seu sexto mês de gravidez foram ignoradas pela Casa de Saúde, que não conseguiu realizar testes urgentes de sangue e urina para verificar se o feto tinha morrido. Os testes foram feitos dois dias depois, o que levou a uma deterioração da condição da Sra. Da Silva Pimentel Teixeira (CEDAW, sessão 49, p. 60).

Quanto à igualdade de gênero, entendeu que

Rev. de Gênero, Sexualidade e Direito | e-ISSN: 2525-9849 | Porto Alegre | v. 4 | n. 2 | p. 1 - 18 | Jul/Dez. 2018 
[...] as medidas para eliminar a discriminação contra as mulheres são consideradas inadequadas em um sistema de saúde que carece de serviços para prevenir, detectar e tratar doenças específicas das mulheres. À luz dessas observações, o Comitê também rejeita o argumento do Estado-parte de que o ofício não continha ligação casual entre o sexo da Sra. da Silva Pimentel Teixeira e os possíveis erros médicos cometidos, mas que as reivindicações diziam respeito à falta de acesso à assistência médica relacionada com a gravidez (CEDAW, sessão 49, p. 60-61).

No que se refere à assistência apropriada à gravidez de Alyne, o Comitê concluiu sua ausência

[...] não somente em relação à incapacidade de realizar um teste de sangue e urina, mas também o fato de que a cirurgia de curetagem só foi realizada 14 horas após a indução do parto, a fim de remover a placenta, que não tinha sido totalmente expulsa durante o trabalho de parto e poderia ter causado a hemorragia e finalmente, a morte. A cirurgia foi feita na Casa de Saúde, que não estava devidamente equipada, e sua transferência para o hospital municipal levou oito horas, sendo que o hospital se recusou a fornecer sua única ambulância para transportar apenas ela, e sua família não conseguiu uma ambulância privada. Também observa que sua transferência para o hospital municipal sem os devidos registros médicos e informações sobre seu histórico médico não teve eficácia, já que ela foi deixada em uma área improvisada no corredor do hospital por 21 horas, até que morreu (CEDAW, sessão 49, p. 61-62).

Ao apreciar o argumento do Estado-parte sobre a impossibilidade de lhe imputar a inadequação dos serviços prestados, já que os fatos ocorreram em uma instituição privada, considerou-se que

[...] o Estado é diretamente responsável pela ação de instituições privadas, quando terceiriza seus serviços médicos, e que, além disso, o Estado mantém sempre o dever de regular e monitorar instituições de saúde privadas. De acordo com o Artigo 2 (e) da Convenção, o Estado-parte tem a obrigação de tomar medidas para assegurar que as atividades dos setores privados no que diz respeito às políticas de saúde e práticas sejam apropriadas. Neste caso particular, a responsabilidade do Estado-parte está fortemente ancorada na Constituição Brasileira (artigos 196-200), que prevê o direito à saúde como um direito humano geral. O Comitê conclui, portanto, que o Estado não cumpriu suas obrigações nos termos do Artigo 12, Parágrafo 2, da Convenção (CEDAW, sessão 49, p. 63).

Para a condenação do Brasil, fundamentou-se, também, que

A falta de serviços de saúde materna adequados no Estado-parte, que claramente não satisfez as necessidades de saúde e interesses específicos das 
mulheres, não só constitui uma violação do Artigo 12, Parágrafo 2, da Convenção, mas também discriminação contra as mulheres nos termos do Artigo 12, Parágrafo 1, e Artigo 2 da Convenção. Além disso, a falta de serviços de saúde materna adequados tem um impacto diferencial sobre o direito à vida das mulheres.

[...] O Comitê observa que o Estado-parte não descartou a possibilidade de que a discriminação tenha contribuído em alguma medida, mas não decisivamente, para a morte da filha do autor. O Estado-parte também reconheceu que a convergência ou associação dos diferentes elementos descritos pelo autor pode ter contribuído para a falta de assistência necessária e emergencial para sua filha, resultando em sua morte. Em tais circunstâncias, o Comitê conclui que a Sra. Da Silva Pimentel Teixeira foi vítima de discriminação, não só com base em seu sexo, mas também com base em sua condição de mulher afrodescendente e seu nível socioeconômico (CEDAW, sessão 49, p. 64-66).

Dessa forma, reconheceu-se a configuração de dano moral em favor da autora do ofício encaminhado ao Comitê da CEDAW (mãe de Alyne) e de danos morais e materiais sofridos pela filha de Alyne, recomendando-se que

1) Sobre o autor e a família da Sra. da Silva Pimentel Teixeira:

Prestar reparação adequada, incluindo indenização financeira, ao autor e à filha da Sra. da Silva Pimentel Teixeira proporcional à gravidade das violações contra ela;

2) Disposições Gerais:

(A) Assegurar o direito das mulheres à maternidade segura e ao acesso à assistência médica emergencial adequada, a preços acessíveis, de acordo com a recomendação geral no 24 (1999) sobre as mulheres e a saúde;

(B) Proporcionar formação profissional adequada para os trabalhadores da área de saúde, especialmente sobre os direitos reprodutivos das mulheres à saúde, incluindo tratamento médico de qualidade durante a gravidez e o parto, bem como assistência obstétrica emergencial adequada;

(C) Assegurar o acesso a medidas eficazes nos casos em que os direitos das mulheres à saúde reprodutiva tenham sido violados e prover a formação de pessoal do poder judiciário e responsável pela aplicação da lei;

(D) Assegurar que as instalações de assistência médica privada satisfaçam as normas nacionais e internacionais em saúde reprodutiva;

(E) Assegurar que as sanções adequadas sejam impostas a profissionais de saúde que violem os direitos de saúde reprodutiva das mulheres, e

(F) Reduzir as mortes maternas evitáveis através da implementação do Acordo Nacional pela Redução da Mortalidade Materna nos níveis estadual e municipal, inclusive através da criação de comitês de mortalidade materna em lugares onde tais comitês ainda não existem, de acordo com as recomendações em suas observações finais para com o Brasil, adotadas em 15 de agosto de 2007 (CEDAW/C/BRA/C0/6).

Referido caso merece destaque, porque foi o primeiro sobre mortalidade materna decidido por um órgão internacional de direitos humanos e corrobora os argumentos 
apresentados nesse estudo de que, para a efetivação dos direitos humanos das mulheres, notadamente os direitos reprodutivos, existe a necessidade de uma atuação positiva do Estado, a fim de implementar, aprimorar e conformar políticas públicas destinadas a resguardar esses direitos.

As diferenças biológicas entre os sexos masculino e feminino impõem a prestação do serviço de saúde de acordo com suas particularidades, sendo indubitável que questões envolvidas à maternidade merecem a adoção de medidas adequadas para a salvaguarda dos direitos femininos. É nesse sentido que se observa a igualdade de gêneros.

Com efeito, o art. $1^{\circ}$ da Convenção dispõe que

Para os fins da presente Convenção, a expressão "discriminação contra a mulher" significará toda a distinção, exclusão ou restrição baseada no sexo e que tenha por objeto ou resultado prejudicar ou anular o reconhecimento, gozo ou exercício pela mulher, independentemente de seu estado civil, com base na igualdade do homem e da mulher, dos direitos humanos e liberdades fundamentais nos campos político, econômico, social, cultural e civil ou em qualquer outro campo.

Especificamente quanto ao direito à saúde, o art. 12 da Convenção prevê que

1. Os Estados-Partes adotarão todas as medidas apropriadas para eliminar a discriminação contra a mulher na esfera dos cuidados médicos a fim de assegurar, em condições de igualdade entre homens e mulheres, o acesso a serviços médicos, inclusive os referentes ao planejamento familiar.

2. Sem prejuízo do disposto no parágrafo $1^{\circ}$, os Estados-Partes garantirão à mulher assistência apropriadas em relação à gravidez, ao parto e ao período posterior ao parto, proporcionando assistência gratuita quando assim for necessário, e the assegurarão uma nutrição adequada durante a gravidez e a lactância.

Verifica-se, portanto, o emprego de um conceito amplo de discriminação, entendida como a inexistência de instrumentos suficientes e adequados que possibilitem a integral realização dos direitos humanos das mulheres, interpretação esta que confere maior força e efetividade aos referidos direitos.

Assim, políticas públicas de gênero devem, necessariamente, constituírem-se em ações que modiquem as desigualdades existentes entre os sexos, o que implica na real garantia dos direitos das mulheres. Isso porque, de acordo com a Convenção Sobre a Eliminação de Todas as Formas de Discriminação Contra a Mulher, a omissão do Poder 
Público para resguardar e viabilizar o verdadeiro exercício de direitos fundamentais pelas mulheres consiste em discriminação.

Portanto, incumbe-se aos Estados preverem e aplicarem políticas públicas que não enfrentem apenas formalmente as diferenças de gênero, sendo necessário que as características específicas das mulheres sejam consideradas de fato, ao se estabelecer as medidas destinadas a assegurar seus direitos.

\section{CONCLUSÃO}

Apesar da pretensa universalização dos direitos humanos estimulada, decisivamente, pela Declaração Universal de Direitos Humanos em 1948, ainda existem diversos obstáculos para sua efetiva concretização, sendo que, atualmente, não se verifica o integral e isonômico exercício dos direitos fundamentais internacionalmente reconhecidos.

Circunstâncias históricas, sociais, econômicas e culturais não apenas motivam a afirmação de direitos humanos, como também impedem a garantia desses direitos isenta de qualquer discriminação. Isso porque, ideais preconcebidos e amplamente difundidos como absolutos criam barreiras para que a sociedade - incluindo homens e mulheres - modifiquem eventuais divergências estabelecidas em razão de raça, gênero ou classe, por exemplo.

A existência dessa discriminação na defesa dos direitos humanos supostamente universais pode ser exemplificada tanto pelo progresso inferior da proteção formal de direitos humanos das mulheres (elaboração de instrumentos normativos que, apesar de afirmarem que todos são livres e iguais para exercerem seus direitos, excluíram as mulheres da própria condição de ser humano), como pela ausência de efetiva custódia desses direitos, o que culmina na desigualdade dos gêneros e nas consequentes discriminações e violências sofridas pelas mulheres.

Dessa forma, justifica-se a elaboração de documentos internacionais específicos para a salvaguarda dos interesses femininos, somada, necessariamente, à adoção de mecanismos que considerem as particularidades das mulheres e, assim, estabeleçam políticas públicas destinadas à concretização dos seus direitos humanos.

Considerar e trabalhar as diferenças do feminino com o masculino, elaborando normas e desenvolvendo ações políticas que tratem individual e divergentemente das garantias a serem exercidas pelas mulheres, quando assim se fizer necessário (como ocorre

Rev. de Gênero, Sexualidade e Direito | e-ISSN: 2525-9849 | Porto Alegre | v. 4 | n. 2 | p. 1 - 18 | Jul/Dez. 2018 
com o direito à saúde), assegura os ideais de igualdade (no seu viés material), de dignidade da pessoa humana e de universalização dos direitos humanos.

Decisões como a proferida pelo Comitê CEDAW, no caso "Alyne v. Brasil", demonstram a preocupação internacional em reverter essa insistente desigualdade de gênero, resultado de discriminações sofridas pelas mulheres no exercício de seus direitos humanos. A promoção da igualdade entre homens e mulheres impõe uma atuação contínua e convergente dos atores sociais.

\section{REFERÊNCIAS}

BOBBIO, Norberto. A Era dos Direitos. Tradução de Carlos Nelson Coutinho. Tradução de L'età dei Diritti. Rio de Janeiro: Elsevier, 2004.

CANÇADO TRINDADE, Antônio Augusto. A proteção internacional dos direitos humanos. São Paulo: Saraiva,1991.

COMPARATO, Fábio Konder. A Afirmação Histórica dos Direitos Humanos. São Paulo: Saraiva, 1999.

COOK, Rebecca J. Human Rights and Maternal Health: Exploring the Effectiveness of the Alyne Decision. Journal of Law, Medicine \& Ethics 41.1 (2013): 103-123. Disponível em $<$ https://www.law.utoronto.ca/utfl_file/count/documents/reprohealth/Pub-

AlynePortuguese.pdf >. Acesso em: 16 ago 2018.

INTERNACIONAL, Comitê Para a Eliminação da Discriminação Contra Mulheres. Alyne Pimentel v. Brasil. Tradução Juramentada. Traduzido por Mariana Erika Heynemann. Disponível em: <http://pfdc.pgr.mpf.mp.br/atuacao-e-conteudos-de-apoio/temas-deatuacao/saude/saude-materna/decisoes/decisao-cedaw-caso-alyne-teixeira-29jul11portugues>. Acesso em: 29 jul. 2018.

LOPES, Aline Luciane. A Mulher e a Construção da Cidadania na Perspectiva dos Direitos Humanos. Revista Argumenta, Jacarezinho, n. 15, p. 223-237, jul-dez. 2011.

JELIN, Elizabeth. Mulheres e Direitos Humanos. Revista Estudos Feministas, v. 2, n. 3, Florianópolis, 1994.

PERROT, Michelle, Práticas de memória feminina. Revista Brasileira de História, v. 9, n. 18, São Paulo, ago./set. 1989)

PIMENTEL, Silvia. Experiências e Desafios: Comitê sobre a Eliminação de Todas as Formas de Discriminação contra a Mulher (CEDAW/ONU) - relatório bienal de minha participação. Brasília: Secretaria Especial de Políticas para as Mulheres, 2008. 92p. (Série Documentos). 
PIOVESAN, Flávia. A Proteção Internacional dos Direitos Humanos das Mulheres. Revista EMERJ, Rio de Janeiro, v. 15, n. 57 (Edição Especial), p. 70-89, jan.-mar. 2012.

Saraiva, 2013.

Direitos Humanos e o Direito Constitucional Internacional. São Paulo:

REPÚBLICA FEDERATIVA DO BRASIL. Relatório do Governo Brasileiro. Comunicado $N^{\circ}$ 17/2008 de 10 de agosto de 2011. Brasília, 2014.

TEDESCHI, Losandro Antonio; COLLING, Ana Maria. Os Direitos Humanos e as Questões de Gênero. Revista da Faculdade de História e do Programa de Pós-graduação em História, Goiânia, v. 19, n. 3, p.33-34, 2014.

TOURAINE, Alain. Um Novo Paradigma: Para Compreender o Mundo de Hoje. Tradução de Gentil Avelino Titton. Petrópolis, RJ: Vozes, 2006.

UNITED NATIONS. Progress Achieved in the Implementation of the Convention on The Elimination of all Forms of Discrimination Against Women: Report by the Committee on the Elimination of Discrimination against Women. 1999. Disponível em: <http://www.un.org/documents/ga/conf177/aconf177-7en.htm>. Acesso em: 02 ago. 2018.

ZINANI, Cecil Jeanine Albert. Literatura e Gênero: A Construção da Identidade Feminina. Caxias do Sul, RS. EDUCS, 2006. 